\title{
A study of role of doppler in gestational hypertension and perinatal outcome
}

\author{
Anjali R. Chavda*, Parul T. Shah, Rina V. Patel, Hemali N. Patel
}

Department of Obstetrics and Gynecology, Smt. NHL Municipal Medical College, SVPIMSR, Ahmedabad, Gujarat, India

Received: 18 May 2020

Accepted: 29 June 2020

*Correspondence:

Dr. Anjali R. Chavda,

E-mail: anjali310794@gmail.com

Copyright: () the author(s), publisher and licensee Medip Academy. This is an open-access article distributed under the terms of the Creative Commons Attribution Non-Commercial License, which permits unrestricted non-commercial use, distribution, and reproduction in any medium, provided the original work is properly cited.

\section{ABSTRACT}

Background: Hypertensive disorder of pregnancy is one of the most common complications that affect the human pregnancy. Hence it is important to identify women at risk of developing gestational hypertension or preeclampsia, its early diagnosis and subsequent consequences due to uteroplacental insufficiency with help of Doppler ultrasound, to improve perinatal outcome. The objective of this study was to study the application of Doppler ultrasound with analysis of blood flow velocity waveform in gestational hypertension and to examine and study the perinatal outcome in pregnancy with altered Doppler indices.

Methods: A prospective study was carried out in 50 antenatal patients diagnosed to have gestational hypertension during a period of 12 months to evaluate the role of color Doppler imaging in gestational hypertension in patients more than 28 weeks of gestation, the initial scan was performed immediately after the diagnosis. This study analyzed the blood flow in umbilical artery, maternal uterine artery and fetal middle cerebral artery using Doppler ultrasound.

Results: In this study approximately $76 \%$ of cases were found in 20-30 years group. 58\% showed abnormal umbilical artery Doppler while $42 \%$ women had normal umbilical artery Doppler. In this study 23 cases had cerebro-placental index $<1$ and 27 cases had cerebro-placental index $>1$. Cases with cerebro-placental index $<1$ had various complications like preterm delivery, low birth weight, increased chances of still birth, intra uterine death (IUD), increased NICU admission. In this study 31 cases had abnormal uterine artery Doppler which accounts for $62 \%$ of total cases, while $38 \%$ had normal uterine artery Doppler.

Conclusions: Doppler ultrasound can reliably predict any adverse fetal outcome in hypertensive pregnancies and can be a useful tool for decision making in appropriate timing of intervention for delivery.

Keywords: Doppler, Gestational hypertension, Intrauterine growth retardation, Middle cerebral artery, Ultrasound, Umbilical artery, Uterine artery

\section{INTRODUCTION}

Hypertensive disorder of pregnancy is one of the most common complications that affect human pregnancy. It is one of the leading causes of maternal and fetal morbidity and mortality. ${ }^{1}$ Pregnancy induced hypertension (PIH) included gestational hypertension, Preeclampsia and eclampsia. PIH has many complications. Most common amongst them is intra uterine growth restriction (IUGR). Perinatal death including intrauterine and early neonatal deaths, hypoxic ischemic encephalopathy, intraventricular hemorrhage, pulmonary hemorrhage and necrotizing enterocolitis. Minor outcome included caesarean section for fetal distress, increases NICU admissions. Other are placental infarcts and abruption. Due to these adverse outcomes the main goal of prenatal testing is to identify the fetus at increased risk for perinatal morbidity and mortality. With the help of early detection modalities, early detection of diseases can have better outcome, through increased surveillance and 
prophylactic use of aspirin..$^{2,3}$ The main defect which is predisposing to uteroplacental insufficiency is partial or incomplete failure of trophoblastic invasion. ${ }^{4}$ Doppler ultrasound is non-invasive method, which gives useful information about impaired blood flow to fetus at risk among high risk patients. The rate of preterm birth, growth retarded fetus and perinatal death are significantly increased in pregnancies complicated by severe preeclampsia. $^{5,6}$

\section{METHODS}

Authors conducted a prospective study of 50 pregnant women with gestational hypertension evaluated with colour Doppler and to be followed subsequently for perinatal outcome. The study was conducted in tertiary care center during the period of 12 months.

\section{Inclusion criteria}

- Pregnant women with gestational hypertension with more than 28 weeks of gestation were included in study. Reference criteria for gestational hypertension were persistently high systolic pressure $(\geq 140$ $\mathrm{mmHg})$ or diastolic pressure $(\geq 90 \mathrm{mmHg})$, with or without proteinuria of new onset after 20 weeks of gestation.

\section{Exclusion criteria}

- Pregnancy with severe congenital anomalies were excluded

- Twin/multiple pregnancy

- Extra uterine pregnancy

- Antenatal case with gestational age less than 28 weeks

- Antenatal case with intrauterine fetal death.

In this study the age of the patients ranged from 19-34 years with their gestational age at time of examination varying from 28 weeks to 39 weeks. The gestational age was confirmed by menstrual history and ultrasound examination. The colour Doppler finding at first examination were taken into consideration. Repetitive Doppler studies were performed whenever required.

Uterine artery: Studied by first identifying the placental site. If placenta was unilateral uterine artery of that side was studied. In case of central placenta, both uterine arteries were evaluated. The main branch of uterine artery is located at cervico-corporal junction. Uterine artery was examined at level of internal os with full bladder seen crossing perpendicular to external iliac artery. Doppler velocimetry measurement was performed near this location.

Umbilical artery: Free-floating loop of umbilical cord was examined to evaluate umbilical artery. Care was taken not to take reading during fetal breathing or gross body movements.
Middle cerebral artery: Middle cerebral artery was evaluated in a transverse section of fetal skull at level of thalami and cavum septum pellucidum. A transverse view of fetal brain was obtained at the level of biparietal diameter.

Ductus venosus: The ductus venosus could be visualized either in midsagittal longitudinal plane of fetal trunk or in oblique transverse plane through the upper abdomen.

\section{RESULTS}

The patients with gestational hypertension were distributed under the age group of $<20,20-25,25-30,30-$ 35 years. Out of 50 patients 21 were under the age group of 20-25 years which accounted for approximately $42 \%$ of all cases. $76 \%$ of patients were between the age group of 20-30 years (Table 1 ).

Table 1: Distribution of gestational hypertension according to age.

\begin{tabular}{|ll|}
\hline Age group (years) & No. of patients \\
\hline$<20$ & $1(2 \%)$ \\
\hline $20-25$ & $21(42 \%)$ \\
\hline $25-30$ & $17(34 \%)$ \\
\hline $31-35$ & $11(22 \%)$ \\
\hline Total & $50(100 \%)$ \\
\hline
\end{tabular}

In this study above table shows the parity according distribution of patients with gestational hypertension (Table 2).

Table 2: Distribution of gestational hypertension according to parity.

\begin{tabular}{|ll|}
\hline Parity & No. of patients. \\
\hline 0 & $20(40 \%)$ \\
\hline 1 & $22(44 \%)$ \\
\hline 2 & $6(12 \%)$ \\
\hline 3 or more & $2(4 \%)$ \\
\hline Total & $50(100 \%)$ \\
\hline
\end{tabular}

Table 3: Distribution of patients according to changes in the umbilical artery doppler (S/D ratio).

\begin{tabular}{|ll|}
\hline Umbilical artery S/D ratio & No. of patients \\
\hline$\geq 3$ & $29(58 \%)$ \\
\hline$<3$ & $21(42 \%)$ \\
\hline Total & $50(100 \%)$ \\
\hline
\end{tabular}

In this study $58 \%$ of women showed abnormal umbilical artery Doppler while $42 \%$ of women had normal umbilical Doppler (Table 3).

In this study $46 \%$ cases had cerebro-placental index $<1$ and $54 \%$ had cerebro-placental index $>1$ (Table 4). 
Table 4: Distribution of patients according to cerebroplacental index (CPI).

\begin{tabular}{|ll|}
\hline Cerebro-placental index & No. of patients \\
\hline$<1$ & $23(46 \%)$ \\
\hline$>1$ & $27(54 \%)$ \\
\hline Total & $50(100 \%)$ \\
\hline
\end{tabular}

Table 5: Perinatal outcome in relation to cerebroplacental index.

\begin{tabular}{|ll|l|}
\hline Events & $\begin{array}{l}\text { Cerebro- } \\
\text { placental } \\
\text { index }<1(\%)\end{array}$ & $\begin{array}{l}\text { Cerebro- } \\
\text { placental } \\
\text { index }>1(\%)\end{array}$ \\
\hline $\begin{array}{l}\text { Gestational age at } \\
\text { delivery (weeks) } \\
\text { mean }\end{array}$ & $\begin{array}{l}36.43 \pm 2.59 \\
\text { weeks }\end{array}$ & $\begin{array}{l}38.26 \pm 0.52 \\
\text { weeks }\end{array}$ \\
\hline $\begin{array}{l}\text { Birth weight }<2500 \\
\text { gms }\end{array}$ & $34(69.56 \%)$ & $9(18 \%)$ \\
\hline $\begin{array}{l}\text { Me conium stained } \\
\text { liquor }\end{array}$ & $26(52.2 \%)$ & $11(11.1 \%)$ \\
\hline $\begin{array}{l}\text { Apgar score }<7 \text { at } 5 \\
\text { minutes }\end{array}$ & $24(47.9 \%)$ & $10(20.4 \%)$ \\
\hline NICU admissions & $28(56.5 \%)$ & $14(27.9 \%)$ \\
\hline IUD/still birth & $16(32.6 \%)$ & $4(8 \%)$ \\
\hline
\end{tabular}

Table 6: Distribution of cases under normal and abnormal Middle cerebral artery indices.

\begin{tabular}{|ll|}
\hline Waveform -MCA & Total \\
\hline I-Increase diastolic flow & $31(62 \%)$ \\
\hline N-normal & $19(38 \%)$ \\
\hline Total & $50(100 \%)$ \\
\hline
\end{tabular}

Table 7: Distribution of cases according to normal and abnormal uterine artery indices.

\begin{tabular}{|ll|}
\hline Uterine artery & Total \\
\hline Abnormal & $31(34 \%)$ \\
\hline Normal & $19(38 \%)$ \\
\hline Total & $50(100 \%)$ \\
\hline
\end{tabular}

Table 8: Distribution of cases with reversal of a wave in ductus venosus.

\begin{tabular}{|ll|}
\hline Ductus venosus waveform & Total \\
\hline A-reversal of wave & $41(82 \%)$ \\
\hline N-normal & $9(18 \%)$ \\
\hline Total & $50(100 \%)$ \\
\hline
\end{tabular}

The Table 5 suggests that the in this study patients who had CPI $<1$ had poor neonatal outcome as compared to the patients who had CPI ratio $>1$ (Table 5). In this study $62 \%$ cases showed increased diastolic flow in the middle cerebral artery which suggests the 'brain sparing effect' in compromising fetus, while other $38 \%$ showed the normal flow in middle cerebral artery (Table 6). In this study, out of 50 cases, 31 cases had abnormal uterine artery Doppler indices accounting for $62 \%$ of total cases and $38 \%$ had normal uterine artery Doppler (Table 7).

In this study, out of 50 cases, 41 cases had reversal in ductus venosus waveform accounting for 825 of total cases and $18 \%$ had normal ductus venosus waveform (Table 8).

\section{DISCUSSION}

Gestational hypertension is a common complication during pregnancy. Introduction of Doppler ultrasound in obstetrics allows us to study the changes in uteroplacental and fetoplacental circulation in adverse conditions like gestational hypertension. By serial Doppler studies, authors can follow the sequence of changes in response to fetal hypoxemia.

Uteroplacental and fetoplacental insufficiency are the primary cause of IUGR and other catastrophic events related to gestational hypertension and can be identified using uterine and umbilical artery Doppler study. In this study umbilical artery, uterine artery and middle cerebral artery were studied with special attention on jeopardized fetus, so that appropriate measures can be taken and perinatal outcome can be improved. In gestational hypertension there is inadequate invasion of spiral arteries leading to increased resistance in spiral arteries. This leads to an increased impedance of blood flow in uterine artery. Fleischer A et al, had similar results in their study. ${ }^{7}$

In this study uterine artery Doppler velocimetry was studied and these finding were consistent with the Khalid M et al. ${ }^{8}$ According to Jackson MR et al, patient with uterine artery notches and high resistance flow had significantly higher rates of fetal growth retardation and caesarean delivery because of fetal distress and had significantly bad pregnancy outcome. ${ }^{9}$

In this study $29(58 \%)$ patients have abnormal umbilical artery Doppler indices while 21 (42\%) patients have normal umbilical artery Doppler.

In this study of 50 patients, 19 patients which account for the $38 \%$ of total have normal middle cerebral artery blood flow while the remaining 31 patients $(62 \%)$ have increased diastolic blood flow with brain sparing effect.

Similar results were found in study by Lakhkar BN et al, who prospectively examined 58 singleton pregnancies beyond 30 weeks of gestation complicated by intrauterine growth restriction and severe pre-eclampsia with Doppler. ${ }^{10}$

Chan et al studied 71 high-risk pregnancies with weekly UA (umbilical artery) and MCA (middle cerebral artery) Doppler ultrasound examination until delivery. ${ }^{11}$ In $15.5 \%$ (11 of 71) of fetuses, there were perinatal mortality or major morbidity, including major intracranial 
hemorrhage, periventricular leukomalacia and other major neurological deficits.

From the last Doppler ultrasound result for analysis, the UA/MCA resistance index ratio was more sensitive $(75 \%$ versus 64\%) but less specific (60\% versus $74 \%)$ compared to UA systolic to diastolic ratio (S/D ratio) UA Doppler ultrasound was a better predictor for each of individual adverse outcome when separate analyses were performed.

In present study, 58\% showed abnormal umbilical artery Doppler study (S/D ratio) and is comparable with other study.

The sensitivity, specificity, positive predictive value and negative predictive value of abnormal uterine artery Doppler as predictor of poor perinatal outcome was $80.00 \%, 82.66 \%, 89.66 \%$ and $69.05 \%$ respectively.

This result was comparable with results of Fleischer et al. ${ }^{12}$ Cerebro-placental index was abnormal in $46 \%$ in present study and had $69.23 \%$ sensitivity, $93.92 \%$ specificity, $95.74 \%$ positive predictive value and $60.78 \%$ negative predictive value respectively for predicting poor perinatal outcome. This is comparable with study of ALLA et al. ${ }^{13}$

\section{CONCLUSION}

Hypertensive disorder of pregnancy is one of the leading causes of maternal morbidity and mortality and is responsible for a considerable amount of perinatal morbidity and mortality.

Doppler ultrasound offers the ability to screen the cases of gestational hypertension with a reproducible noninvasive hemodynamic testing mechanism. Fetus with abnormal Doppler velocimetry had a significant higher incidence of low birth weight, low Apgar score, meconium stained liquor, IUGR, admission to NICU, IUD/still births and preterm deliveries.

Doppler indices from the fetal circulation can reliably predict adverse perinatal outcome in obstetrics patients with gestational hypertension. Doppler data combining both umbilical and cerebral velocimetry provide additional information on fetal consequences of the placental abnormality.

Doppler ultrasound has provided to reliably predict the any adverse fetal outcome in hypertensive pregnancies and can be useful tool for taking decision in appropriate timing of intervention for delivery.

The Doppler pattern follow the longitudinal trend with early changes in the umbilical artery followed by middle cerebral artery and other peripheral artery.
Venous changes follow the arterial pattern and occur in severely compromised fetus. Doppler investigation plays an important role in monitoring the redistributing growth restricted fetus and thereby may help in determine the optimal time for delivery.

Funding: No funding sources

Conflict of interest: None declared

Ethical approval: The study was approved by the Institutional Ethics Committee

\section{REFERENCES}

1. Zeeman GG, Dekkor GA. Pathogenesis of preeclampsia: a hypothesis. Clin Obstet Gynecol. 1992;35:317-37.

2. McParland P, Pearce JM, Chamberlain GV. Doppler ultrasound and aspirin in recognition and prevention of pregnancy-induced hypertension. Lancet. 1990;335(8705):1552-5.

3. Uza, Hadda. Uteroplacental Doppler Ultrasound. Obstet Gynaecol. 1994;4:2.

4. Khong TY, De Wolf F, Robertson WB, Brosens I. Inadequate maternal vascular response to placentation in pregnancies complicated by preeclampsia and by small-for-gestational age infants. An Int J Obstet Gynaecol. 1986;93(10):1049-59.

5. Lin CC, Lindheimer MD, River P. Fetal outcome in hypertensive disorders of pregnancy. Am J Obstet Gynecol. 1982;142:255.

6. Sibai B, Spinnato JA, Watson DL. Pregnancy outcome in 303 cases with severe preeclampsia. Obstet Gynecol. 1984;64:319-21.

7. Fleischer A, Schulman H, Farmakides G, Bracero L, Grunfeld L, Rochelson B, Koenigsberg M. Uterine artery Doppler velocimetry in pregnant women with hypertension. Am J Obstet Gynecol. 1986;154:80613.

8. Khalid M, Wahab S, Kumar V, Khalid S, Haroon S, Sabzposh NA. Doppler indices in prediction of fetal outcome in hypertensive pregnant women. Nepal J Obstet Gynaecol. 2011;6(1):28-34.

9. Jackson MR, Walsh AJ, Morrow RJ, Muller BM, Lye SJ, Ritchie JK. Reduced placental villous tree elaboration in small-for-gestational-age pregnancies: relationship with umbilical artery Doppler waveforms. Am J Obstetrics Gynecol. 1995;172(2):518-25.

10. Lakhkar BN, Rajgopal KN, Gourishankar Pt. Doppler prediction in intrauterine growth retardation IJRI. 2006;16(1):109-16.

11. Chan FY, Pun TC, Lam P, Lam C, Lee CP, Lam YH. Fetal cerebral Doppler as a predictor of perinatal outcome and subsequent neurological handicap. Obstet Gynecol. 1996;87:981-8.

12. Fleischer A, Schulman H, Farmakides G, Bracero L, Blattner P, Randolph G. Umbilical artery velocity waveforms and intrauterine restriction. Am J Obstet Gynecol. 1985;151:502-5. 
13. Ebrashy A, Azmy O, Ibrahim M, Waly M, Edris A. Middle cerebral/umbilical artery resistive index as sensitive parameter for fetal wellbeing and neonatal outcome in patients with pre-eclampsia: Casecontrol study. Croat Med J. 2005;46:821-5.
Cite this article as: Chavda AR, Shah PT, Patel RV, Patel HN. A study of role of doppler in gestational hypertension and perinatal outcome. Int J Reprod Contracept Obstet Gynecol 2020;9:3458-62. 